\title{
Bilingualism affects picture naming but not picture classification
}

\author{
TAMAR H. GOLLAN \\ University of California, San Diego, La Jolla, California \\ ROSA I. MONTOYA \\ University of California, San Diego, La Jolla, California \\ and Veterans Medical Research Foundation, San Diego, California \\ CHRISTINE FENNEMA-NOTESTINE \\ University of California, San Diego, La Jolla, California \\ and Veterans Affairs Healthcare System, San Diego, California \\ and \\ SHAUNNA K. MORRIS \\ University of California, San Diego, La Jolla, California \\ and Veterans Medical Research Foundation, San Diego, California
}

\begin{abstract}
Bilinguals named pictures in their dominant language more slowly (and with more errors) than did monolinguals. In contrast, bilinguals named the same pictures as quickly as did monolinguals on the fifth presentation (in Experiment 2) and classified them (as human made or natural) as quickly and accurately as did monolinguals (in Experiment 1). In addition, bilinguals retrieved English picture names more quickly if they knew the name in both Spanish and English (on the basis of a translation test that bilinguals completed after the timed tasks), and monolingual response times for the same materials suggested that this finding was not obtained simply because names that were easier to translate were easier in general. These findings suggest that bilinguals differ from monolinguals at a postconceptual processing level, that implicit activation of lexical representations in the nontarget language can facilitate retrieval in the target language, and that being bilingual is analogous to having a lexicon full of lower frequency words, relative to monolinguals.
\end{abstract}

The ability to speak more than one language proficiently is a coveted skill. Although monolingualism is quite common among English speakers, often this is not because monolinguals wish to remain monolingual but, rather, because their attempts to become bilingual have failed. In most parts of the world, bilingualism is the rule, not the exception (Harris \& McGhee Nelson, 1992), although bilinguals and researchers of bilingualism recognize that truly balanced bilinguals (i.e., bilinguals with nativelike

Part of this research was submitted as R.I.M.'s undergraduate honors thesis for a BA from the University of California, San Diego.This research was supported by Career Development Award DC00191 from NIDCD to T.H.G., by a McNair Fellowship from the University of California San Diego to R.I.M., by an Individual Investigator Award from the State of California DHS Alzheimer's Disease Program to Terry L. Jernigan, by a Research Enhancement Award Program from the Office of Research and Development Department of Veterans Affairs Medical Research Service that supported C.F.-N., and by NIMH Grant R01MH64733 to Vic Ferreira. We thank Terry Jernigan for valuable comments on an earlier version of this article and Cynthia Cera for assistance with data collection. Correspondence concerning this article should be addressed to T. H. Gollan, Department of Psychiatry, University of California, San Diego, 9500 Gilman Drive, La Jolla, CA 92093-0949 (e-mail: tgollan@ucsd.edu). proficiency in both languages) are quite rare, if they exist at all (Grosjean, 1997). Instead, bilinguals commonly report that one language is their dominant language. In addition, it is not unusual to encounter bilinguals who report that their proficiency in both languages, even the dominant language, is less than what it would be if they were to speak just one language. Such bilinguals sometimes comment that they are "losing" their first language (L1) but still cannot speak the second language (L2) "like a native speaker," suggesting that bilinguals may be less fluent in any single language than are people who speak the same language all the time, or monolinguals.

In fact, some studies suggest that achieving and maintaining proficient bilingualism does come with a subtle cost to the dominant language. Bilingual effects on the dominant language were reported both when the dominant language was also L1 (Ransdell \& Fischler, 1987) and in switched dominance bilinguals (i.e., when L2 became dominant; for a review see Michael \& Gollan, 2005). Relative to monolinguals, bilinguals named fewer pictures correctly on standardized tests of confrontation naming such as the Boston Naming Test (Kohnert, Hernandez, \& Bates, 1998; Roberts, Garcia, Desrochers, \& Hernandez, 2002). Similar results were found using experimental measures. 
For example, bilinguals reported more tip-of-the-tongue (TOT) states. This finding generalized to many different types of bilinguals, including Hebrew-English (Gollan \& Silverberg, 2001), Spanish-English, and Tagalog-English bilinguals, and was obtained even when bilinguals were tested in their dominant language exclusively (Gollan \& Acenas, 2004). The TOT state is a striking type of dysfluency (or retrieval failure). Individuals experiencing a TOT are confident that they know the word, feel that recall is imminent, and sometimes report partial characteristics of the target word (e.g., the initial sound; R. Brown \& McNeill, 1966). Although dramatic, TOTs occur relatively infrequently, approximately once or twice a week (A. Brown, 1991), and involve failed, rather than successful, lexical retrieval.

Other evidence that bilingualism may affect the dominant language comes from intact production in the verbal fluency task, a task that is commonly used in cognitive assessments. In a verbal fluency task, participants are typically given $60 \mathrm{sec}$ to produce verbally (or in writing) as many exemplars of a given category as possible. Often, the categories include some semantic categories (e.g., animals, fruits, and vegetables) and some letter categories (e.g., words that begin with the letter F, A, or S). Two recent studies demonstrated that bilinguals produced fewer exemplars in verbal fluency tasks, relative to age- and education-matched monolinguals. In one study, college-aged Spanish-English bilinguals produced significantly fewer correct responses in 9 of 12 semantic categories (with trends in the same direction in 2 of the 3 remaining categories) and 6 of 10 letter categories, and the difference between participant groups was larger and more robust on semantic categories (Gollan, Montoya, \& Werner, 2002). Similarly, in a study of healthy older adults, Spanish-English bilinguals produced fewer correct responses, relative to monolinguals, in 2 semantic, but not in 2 letter, categories that were tested (only 4 categories total were tested in this study; Rosselli et al., 2000). As was described earlier regarding increased TOT rates in bilinguals, the lower verbal fluency scores in both studies could not be attributed solely to language dominance; bilinguals produced fewer correct responses even when they were tested exclusively in their dominant language.

\section{The Locus of Processing Differences Between Bilinguals and Monolinguals}

Current models of bilingual processing need to explain why bilinguals differ from monolinguals on some tasks and to predict when bilinguals will perform similarly to monolinguals. Bilingualism also produces some cognitiveprocessing advantages (Ransdell, Arecco, \& Levy, 2001; for a review, see Bialystok, 2005), and although we will not focus on them here, it is worth noting that betweengroups differences of any kind can be used to constrain models of cognitive processing. A consensus among researchers of bilingualism is that semantic representations are shared across languages and that these are connected to separate word-level representations in each language. The notion of shared semantics between languages is virtually unchallenged, particularly for concrete objects; relative to abstract words, concrete words are more likely to be translated in just one way (Tokowicz, 2000) and more often lead to the same semantic associations across languages (van Hell \& de Groot, 1998).

Several studies have supported the shared semantics proposal. ${ }^{1}$ For example, cross-language semantic priming occurs under masked conditions (de Groot \& Nas, 1991) and with a very short interval between the prime and the target (Keatley, Spinks, \& de Gelder, 1994). Stroop effects occur across languages (Tzelgov, Henik, \& Leiser, 1990), and translation is affected by semantic manipulations (Kroll \& Stewart, 1994). The evidence for shared semantics between languages is also quite convincing when high-level problem solving or decision making is involved (Francis, 1999a). Several recent reviews of the studies that support the shared semantics assumption are available (e.g., Francis, 1999b, 2005; Gollan \& Kroll, 2001; Keatley, 1992; Kroll, 1993; Kroll \& de Groot, 1997; Kroll \& Dijkstra, 2002; Smith, 1997).

The assumption that meanings are shared between languages leads to the prediction that bilinguals should perform just like monolinguals when the task primarily requires or emphasizes conceptual processing. In contrast, bilinguals should differ from monolinguals when the task emphasizes the lexical level, because bilinguals must maintain access to roughly twice as many lexical representations. To test these predictions, we compared Spanish-English bilinguals with English-speaking monolinguals on picture naming and picture classification. We used picture naming and picture classification because the same materials could be used in both tasks, thereby ruling out the possibility that differences in the types of stimuli used across tasks could account for the findings. We assumed that picture classification requires participants to access meaning, but not lexical knowledge. Thus, bilinguals and monolinguals should perform picture classification equally well. In contrast, picture naming clearly requires activating lexical knowledge specific to the target language, and thus between-groups processing differences should arise in picture naming. If bilinguals performed equally well as monolinguals when the task did not require access to language-specific lexical representations, it would localize the processing difference after semantic processing.

\section{EXPERIMENT 1: Picture Naming Versus Classification}

We focused on the comparison between Englishspeaking monolinguals and English-dominant bilinguals and tested the bilinguals in English only, because it would not be surprising to find a bilingual disadvantage when bilinguals are tested in their less dominant language or when the testing procedure overtly activates both languages (e.g., by asking bilinguals to name in both languages; such procedures could introduce task-dependent differences between bilinguals and monolinguals). We defined strong-English 
bilinguals as those who reported English to be their dominant language, reported equal proficiency in English and Spanish, or reported that their English was as good as that of a native English speaker (these reports were not mutually exclusive; see the Participants section). It is important to determine whether strong-English bilinguals nevertheless perform less well, relative to monolinguals, both for constraining models of bilingual language processing and for determining what constitutes normal performance for bilinguals. We will discuss two possible mechanisms that predict that bilinguals should be slower and more error prone, relative to monolinguals, when naming pictures.

\section{Cross-Language Interference}

An obvious mechanism that could account for bilingual disadvantages in tasks that focus on lexical processing is interference between languages. Researchers of language production agree that lexical selection involves competition between semantically related lexical representations (Wheeldon \& Monsell, 1994). If competition for selection can occur between languages, bilinguals would be faced with a more difficult task and could respond only after competition both within and between languages was resolved. For example, when Spanish-English bilinguals attempt to name a picture of a cat, they will, much like monolinguals, have to select the desired target from both within-language competitors (e.g., $d o g$ ) and translationequivalent competitors (i.e., gato, the Spanish word for cat). Several recent studies support the notion of crosslanguage interference and, in particular, strongly suggest that the activation of $\mathrm{L} 1$ can interfere with processing in L2. For example, Lee and Williams (2001) showed that naming a picture in L1 (e.g., camel) slowed subsequent naming of a related picture in L2 (e.g., horse in French; see Wheeldon \& Monsell, 1994, for similar competitor priming effects in monolinguals). In another study, fluent Dutch-English bilinguals were slower to name a picture in English (their L2) when distractor words (in either language) were phonologically related to the target's translation equivalent (Hermans, Bongaerts, de Bot, \& Schreuder, 1998). For example, the distractor word bench slowed naming times for a picture of a mountain, presumably because the Dutch word for mountain is berg, which is similar to the distractor bench. The latter finding is quite compelling, because L1 appeared to be active even when the task was carried out exclusively in L2 (i.e., stimuli in L1 were never presented explicitly).

Other studies whose focus was on word recognition and word naming (rather than picture naming) also have suggested that it is difficult for bilinguals to suppress activation of the nontarget language and that such activation may cause interference (Bijeljac-Babic, Biardeau, \& Grainger, 1997; Jared \& Kroll, 2001; van Heuven, Dijkstra, \& Grainger, 1998). However, the possibility of using cross-language interference to explain bilingual disadvantages in their dominant language depends critically on the availability of evidence that L2 may interfere with L1 (i.e., data showing that L1 may interfere with L2 are less relevant). However, generally, effects of L2 on L1 are less robust (but see studies on language switching for an exception; Costa \& Santesteban, 2004; Meuter \& Allport, 1999). In one study, L2 interfered with L1, but only if L2 was first activated by an exclusively L2 task (Jared \& Kroll, 2001), and in other cases, the effects were simply weak (e.g., significant only by participants analyses, and not by items analyses; van Heuven et al., 1998).

Importantly, dual-language activation does not always produce interference. In fact, sometimes, facilitation effects were observed. For example, bilinguals named pictures more quickly when the pictures were presented with written translation-equivalent distractors, even though translation equivalents are precisely the stimuli that should produce the greatest cross-language competition (Costa \& Caramazza, 1999; Costa, Miozzo, \& Caramazza, 1999). Similar facilitation effects were found using an implicit manipulation of dual-language activation. Gollan and Acenas (2004) reported that bilinguals had fewer TOTs for words that most bilinguals could translate, or high-translatability targets, than for words that most bilinguals were unable to translate, or low-translatability targets. Monolingual TOT rates for the same materials suggested that this result could not be attributed to translatable materials simply being easier.

Translatability facilitation effects challenge the notion of cross-language interference; they suggest that rather than competing for selection, at least in some cases, translations actually cue each other. However, TOT data are only problematic (for any account) to the extent that TOT rates can be assumed to also reflect processes involved in intact lexical retrieval. Because TOTs must also involve processes that are not part of fluent retrieval (e.g., TOTs may involve problem solving and/or explicit attempts to self-cue target retrieval), it is important to determine whether translatability also affects intact lexical retrieval. In the present study, we assessed translatability effects on picture-naming times. If translatability facilitation effects in Gollan and Acenas (2004) arose because of a processing mechanism unique to TOT states, a different pattern of results might be expected when timed picture naming is used as the dependent variable.

\section{Weaker Links Between Semantics and Each Lexical System}

Another mechanism for the bilingual advantage assumes a very indirect effect of bilingualism on lexical retrieval. Because bilinguals speak two languages, they, by definition, speak each language less often than do monolinguals. Consequently, bilinguals use words in each language less frequently than do monolinguals, and as such, lexical representations (in both languages) in the bilingual system will have accumulated less practice overall, relative to lexical representations in the monolingual system. Over time, bilingual patterns of language use should lead to weaker links between semantics and phonology in each lexical system, relative to monolinguals, because words that are produced more often are easier to produce. This 
account of the bilingual effect on speaking relies on the same mechanisms as those that produce word frequency effects in monolinguals (and bilinguals).

To test the persistence of any observed differences between groups, one third of the pictures were repeated three times. If the difference between groups disappeared with just one or two repetitions, it would further constrain all possible accounts of the bilingual disadvantage. The weaker links account, in particular, predicts that the difference between bilinguals and monolinguals should disappear with repetition. This prediction is based on the analogy between bilingualism and frequency and the fact that, with repetition, monolinguals name pictures with low-frequency names as quickly as pictures with highfrequency names (Griffin \& Bock, 1998; but see Levelt, Roelofs, \& Meyer, 1999).

\section{Method}

\section{Participants}

We recruited 31 English-speaking monolinguals and 31 SpanishEnglish bilinguals who were undergraduates at the University of California at San Diego to participate in the experiment for course credit. The terms bilingual and monolingual have been defined in different ways by different investigators. The bilinguals in this study had learned both languages at an early age and in natural settings (usually at home). No special attempts were made to recruit monolinguals who had never been exposed to an L2 at all (such individuals would be unusual, given foreign language study requirements); however, although monolinguals may have had some limited exposure to an L2 at a later age, it was only in classroom settings, and none reported having become fluent bilinguals (see Table 1).

The majority $(n=24)$ of the bilinguals reported being English dominant or speaking both English and Spanish as well as "a native speaker" in a language history questionnaire. In the strong-English group, there were 8 bilinguals who reported both their English and their Spanish to be as good as that of a native speaker (i.e., a 7), 5 bilinguals who rated themselves as nativelike in English and very good (i.e., a 6) in Spanish, 4 bilinguals who rated themselves as nativelike in English and good (i.e., a 5) in Spanish, 6 bilinguals who rated themselves as very good in both languages, and 1 bilingual reported a very good rating in English and functional (i.e., a 4) in Spanish. The remaining bilinguals $(n=7)$ reported being Spanish dominant, and their data were not included in the results reported below because, as was noted above, it would not be surprising to find longer picture naming times in the less dominant language (English in this case). We do note, however, that Spanish-dominant bilinguals demonstrated the same pattern of results that we reported below for the strong-English group (for all comparisons, including picture naming, picture classification, and translatability effects).

Table 1 shows average participant characteristics obtained from the language questionnaire. Monolinguals and bilinguals did not differ significantly in average age $[t(53)=1.05, S E=0.48, p=$ $.30]$, and strong-English bilinguals' self-rated ability to speak English tended to be lower than monolinguals' self-ratings for spoken English $[t(53)=2.05, S E=0.11, p=.05]$. In contrast, other differences between groups were quite robust. On average, the participants in the bilingual group reported using another language on a daily basis more often than did monolinguals; they learned English at an older age, learned to speak two languages at a younger age, and rated themselves as having a higher level of proficiency in a language other than English. All of these differences were tested in two-tailed $t$ tests and were significant at the $p<.01$ level.

\section{Materials}

A total of 180 pictures chosen from Snodgrass and Vanderwart (1980) were divided into two sets of 90 pictures and were assigned to either List A or B. An additional 15 pictures were used as practice items ( 8 in List A and 7 in List B). Thirty pictures in each list were shown three times, and 60 pictures were shown only once; thus, collapsing across Lists A and B, there were 60 repeated items and 120 nonrepeated items. In each list, the same picture was never presented on consecutive trials; the average lag between first and subsequent presentations was $12.33(S D=2.62)$, with a minimum of 5 and a maximum of 25 . Picture characteristics are shown in Table 2, including familiarity, image agreement (a subjective rating of how well each picture matches participants' mental images of what they would expect the object to look like), visual complexity, length in syllables of the picture name, and the word form frequency of the picture name. There were no significant differences (all $t \mathrm{~s}<$ 1) between repeated and nonrepeated pictures in these characteristics, with the exception of name length in syllables; nonrepeated picture names were, on average, less then half $(0.37)$ a syllable shorter than repeated picture names $[t(178)=2.70, S E=0.14, p=.04]$.

Table 1

Averages and Standard Deviations for Participant Characteristics for Both Experiments 1 And 2

\begin{tabular}{|c|c|c|c|c|c|c|c|c|}
\hline \multirow[b]{5}{*}{ Characteristic } & \multicolumn{4}{|c|}{ Experiment 1} & \multirow{2}{*}{\multicolumn{4}{|c|}{ Experiment 2}} \\
\hline & \multirow{3}{*}{\multicolumn{2}{|c|}{$\begin{array}{c}\text { Strong- } \\
\text { English } \\
\text { Spanish-- } \\
\text { English } \\
\text { Bilinguals } \\
(n=31) \\
\end{array}$}} & \multirow{3}{*}{\multicolumn{2}{|c|}{$\begin{array}{c}\text { Mono } \\
(n=31)\end{array}$}} & & & & \\
\hline & & & & & \multirow{2}{*}{\multicolumn{2}{|c|}{$\begin{array}{l}\text { Spanish- } \\
\text { English } \\
\text { Bilinguals } \\
(n=36)\end{array}$}} & \multirow{2}{*}{\multicolumn{2}{|c|}{$\begin{array}{c}\text { Mono } \\
(n=36)\end{array}$}} \\
\hline & & & & & & & & \\
\hline & $M$ & $S D$ & $M$ & $S D$ & $M$ & $S D$ & $M$ & $S D$ \\
\hline Age & 20.3 & 1.8 & 19.7 & 1.8 & 20.2 & 2.0 & 20.6 & 2.1 \\
\hline Percent daily use of English & 78.0 & 15.9 & 99.9 & 0.3 & 79.8 & 22.0 & 99.6 & 1.7 \\
\hline Age exposed to English & 4.0 & 2.3 & 0.3 & 0.2 & 3.5 & 0.5 & 0.1 & 0.4 \\
\hline Age exposed to other language & 0.1 & 0.3 & 12.8 & 3.8 & 0.5 & 1.1 & 11.2 & 4.5 \\
\hline English self-rated speaking* & 6.7 & 0.5 & 6.9 & 0.4 & 6.3 & 0.9 & 7.0 & 0.2 \\
\hline Other language self-rated speaking* & 6.1 & 0.8 & 2.4 & 1.0 & 6.1 & 1.0 & 2.8 & 1.0 \\
\hline
\end{tabular}

*Proficiency level based on self-ratings using a scale of $1-7$, with 1 being little to no knowledge and 7 being like a native speaker. Also collected but not shown here were participants' self-ratings for written production, reading, and spoken language comprehension. On average, these ratings never differed by more than 1 point (in either direction) from the ratings for the spoken language. Mono $=$ monolinguals. 
Table 2 Characteristics of Picture Materials in Experiment 1

\begin{tabular}{|c|c|c|c|c|}
\hline \multirow[b]{3}{*}{ Characteristic } & \multicolumn{4}{|c|}{ Pictures } \\
\hline & \multicolumn{2}{|c|}{$\begin{array}{l}\text { Repeated } \\
(n=60)\end{array}$} & \multicolumn{2}{|c|}{$\begin{array}{c}\text { Nonrepeated } \\
(n=120)\end{array}$} \\
\hline & $M$ & $S D$ & $M$ & $S D$ \\
\hline Familiarity* & 3.12 & 0.79 & 3.15 & 0.95 \\
\hline Image-agreement* & 3.74 & 0.59 & 3.69 & 0.56 \\
\hline Visual complexity* & 3.14 & 0.89 & 3.05 & 0.90 \\
\hline Name length in syllables & 2.05 & 0.93 & 1.67 & 0.85 \\
\hline Name frequency/million ${ }^{\dagger}$ & 22.55 & 40.46 & 44.73 & 103.11 \\
\hline
\end{tabular}

However, note that in all of the analyses below, responses are never compared across repeated and nonrepeated materials; rather, the comparison of interest is between participant types within each stimulus set.

Half of the repeated and half of the nonrepeated pictures in each counterbalanced list were of human-made objects, and half were of natural kinds. Pictures with cognate names (e.g., flower and flor) were included to the extent that they occurred naturally in the picture database. There were 20 cognates in each list, 10 repeated and 10 not repeated. It was important to include cognates in order to maintain external validity; cognates are present in normal language production and may activate the nontarget language. Spanish-English cognates are quite common. For example, although they certainly were not designed with Spanish-English bilinguals in mind, 25/60 of the pictures in the Boston Naming Test (Goodglass \& Kaplan, 1987) and 54/260 of the pictures in Snodgrass and Vanderwart (1980) have cognate names. To prepare the participants for the repetition manipulation, some of the practice items were repeated (both during the practice session and after some of the first experimental trials).

\section{Procedure}

The participants were tested individually in sessions lasting $1-1.5 \mathrm{~h}$ in a small testing room, with the experimenter present (R.I.M.). The participants were instructed to name or classify the pictures as human made or natural as quickly as possible without making mistakes. The pictures were presented using PsyScope 1.2.3 (Cohen, MacWhinney, Flatt, \& Provost, 1993) on Macintosh computers with 17 -in. color monitors. Each task was preceded by 10 practice trials. At the beginning of each task (picture naming or classification), the word FOCUS appeared centered on the screen, and when the participant indicated being ready, the experimenter initiated the task with a mouse click. A plus sign appeared at the center of the screen for $3 \mathrm{sec}$, followed by the first picture. Each picture remained on the screen until the participant responded. The participants named pictures in English and were encouraged to guess if they were unsure of the target name and to say "don't know" or "pass" if they could not guess. Reaction times (RTs) were recorded with headset microphones connected to cassette recorders and PsyScope response boxes. Picture-naming and voice-key accuracy was monitored by the experimenter online and was double-checked prior to data analysis, using the audiocassettes. Picture classification RTs were recorded by the response box. The participants were instructed to use the right index finger (or thumb) and the button on the far right for human made and the left index finger (or thumb) and the button on the far left for natural decisions. List and task presentation were counterbalanced across participants, such that half the participants named pictures first and half made picture classifications first; and half named the pictures in List A and performed picture classification on the pictures in List $\mathrm{B}$, and vice versa for the other half. After completing the computer-presented portion of the experiment, the participants were given a language and medical his- tory questionnaire in order to assess their language background and to exclude participants with risk factors for cognitive impairment. Subsequently, the participants were asked to translate, from English to Spanish, all the names of the pictures they saw in both tasks. Translation data were collected in a paper-and-pen format.

\section{Results and Discussion}

Means and standard deviations of RTs for correct responses and error rates were calculated separately for each participant. Correct naming responses were the dominant responses in Snodgrass and Vanderwart (1980), except for four items that were changed because all, or most, of the participants used a different name (i.e., instead of frying pan, garbage bin, pocketbook, and spool of thread, the participants responded pan, trash can, purse, and thread, respectively). The number of nondominant responses was virtually identical across groups (7\% for monolinguals and strong-English bilinguals). RTs for nondominant but acceptable naming responses (e.g., wine bottle instead of bottle) were not included in the analysis of RTs but were not considered errors. All RTs greater than two standard deviations from each participant's mean (of correct responses only) were eliminated. This procedure led to trimming of $4.8 \%$ of monolingual RTs and $4.4 \%$ of strong-English bilingual RTs in picture naming and 5.4\% of monolingual RTs and 5.2\% of strong-English bilingual RTs in picture classification.

For all comparisons, separate ANOVAs were carried out using participant means $\left(F_{1}\right)$ and item means $\left(F_{2}\right.$; the means shown in the figures are $F_{1}$ means). Items analyses were carried out twice: once including all available RTs and once excluding items from both participant groups (and all three presentations) if a data point was missing (either because no participant in that group named the picture correctly or because a repeated item was not named correctly by any participant on the first presentation). This procedure led to the exclusion of 7/30 items in the repeated trials and 14/120 items in the nonrepeated trials in the picture-naming data. In the picture classification data, this procedure led to the exclusion of only 1 nonrepeated item. The same pattern of results was obtained in both items analyses (with and without excluded items); we will report the analysis excluding stimuli that produced missing data points, because the group comparisons are more meaningful when they include only materials that at least some participants from all groups named or classified correctly. Unless otherwise indicated, an alpha level of .05 was adopted for all statistical tests, and when $t$ tests are reported, they are two-tailed tests.

\section{Picture Naming}

In the analysis of nonrepeated pictures, mean RTs and error rates were submitted to an ANOVA with participant type as a between-subjects variable. The mean RT and proportion of errors in each picture-naming condition are shown in Figure 1 (with RTs at the top and errors at the bottom of the figure). In the RT data, there was a main effect of participant type, with strong-English bilinguals naming nonrepeated pictures more slowly than 


\section{Picture Naming}
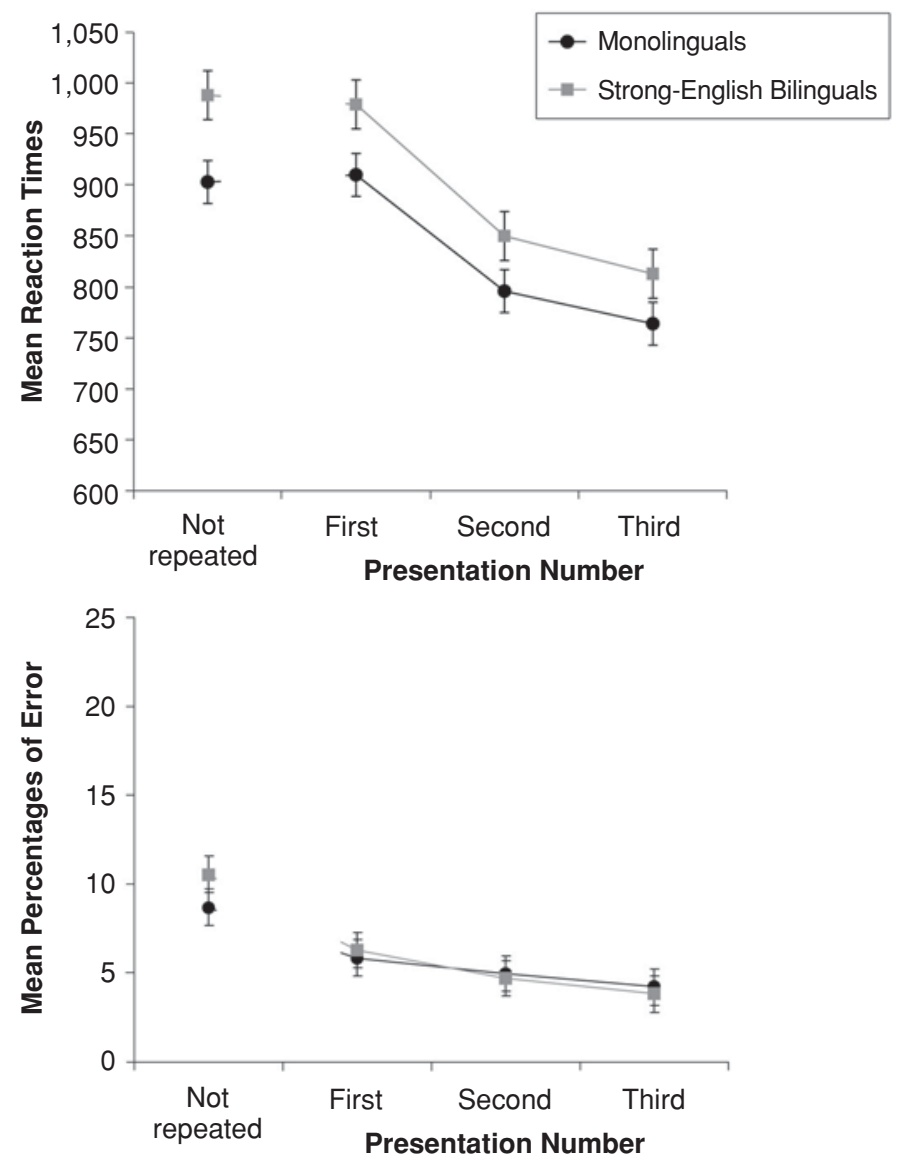

Figure 1. Mean picture-naming reaction times (top panel; in milliseconds) and error rates (bottom panel) for nonrepeated $(n=120)$ and repeated $(n=60)$ pictures in monolinguals and strong-English bilinguals in Experiment 1. Error bars show the standard error of the mean for each participant group. The bilingual effect on naming times was robust for two separate sets of materials, including pictures that were repeated $(n=60)$ and pictures that were not repeated $(n=120$; see Table 2$)$.

did monolinguals $\left[F_{1}(1,53)=6.07, M S_{\mathrm{e}}=16,147.87\right.$, $\left.p=.02 ; F_{2}(1,210)=13.61, M S_{\mathrm{e}}=29,726.21, p<.01\right]$. There were no significant differences between groups in the number of errors $\left[F_{1}(1,53)=2.26, M S_{\mathrm{e}}=.0002, p=\right.$ $\left..14 ; F_{2}<1\right]$.

Repetition effects. In the analysis of repeated pictures, mean RTs and error rates were submitted to two $2 \times$ 3 ANOVAs with participant type as a between-subjects variable (monolingual and strong-English bilingual) and repetition as a repeated measures variable (i.e., first, second, and third presentations). Main effects of repetition were highly robust; with successive repetitions, there were shorter RTs $\left[F_{1}(1,53)=471.09, M S_{\mathrm{e}}=1,399.16\right.$, $\left.p<.01 ; F_{2}(1,104)=139.53, M S_{\mathrm{e}}=10,125.41, p<.01\right]$ and fewer errors $\left[F_{1}(1,53)=19.69, M S_{\mathrm{e}}=0.0005, p<\right.$ $\left..01 ; F_{2}(1,118)=21.35, M S_{\mathrm{e}}=0.001, p<.01\right]$.
The results for repeated pictures were similar to those just reported for nonrepeated pictures. There was a main effect such that strong-English bilinguals named repeated pictures more slowly, relative to monolinguals; in the RT data, this effect was marginally significant by participants $\left[F_{1}(1,53)=3.67, M S_{\mathrm{e}}=36,332.46, p=.06\right]$ and was significant by items $\left[F_{2}(1,104)=8.73, M S_{\mathrm{e}}=26,989.53\right.$, $p<.01]$. The bilingual disadvantage remained constant after three repetitions; the disadvantage was still present when restricted to RT data from the third repetition [i.e., significant by items, but not by participants in the RT data; $F_{1}(1,53)=2.60, M S_{\mathrm{e}}=12,342.30, p=.11 ; F_{2}(1,104)=$ $\left.6.59, M S_{\mathrm{e}}=9,048.83, p=.01\right]$. There was no bilingual disadvantage in the error data (both $F \mathrm{~s}<1$ ). That the effects of participant type were not as robust in the analysis of repeated pictures suggests that the bilingual disadvan- 
tage was not sufficiently robust to be detected with just 30 pictures. With 60 pictures, the bilingual disadvantage was robust (see the results above for nonrepeated pictures).

Against the proposal that bilingualism is analogous to having lower frequency lexical representations, relative to monolinguals, strong-English bilinguals and monolinguals appeared to benefit from repetition to the same extent, as was indicated by the lack of interaction between participant type and repetition in the RT data $\left[F_{1}(1,53)=\right.$ 2.03, $\left.M S_{\mathrm{e}}=1,399.16, p=.16 ; F_{2}<1\right]$ and in the error data $\left[F_{1}<1 ; F_{2}(1,118)=1.31, M S_{\mathrm{e}}=0.003, p=.26\right]$. However, two repetitions may not have been enough to make up the differences in language use over time between this group of bilinguals and their monolingual peers. This hypothesis was tested in Experiment 2, a second picture-naming experiment, in which we presented each picture five times.

Note that repeated and nonrepeated materials appeared to be well matched for difficulty, on the basis of RTs (see Figure 1), but not on the basis of error rates (participants made more naming errors on the nonrepeated materials). The reason for this difference is not clear, particularly given that the only difference we identified between the repeated and the nonrepeated materials was a small difference in the wrong direction in name length (see the Materials section). That is, nonrepeated pictures had slightly shorter names and therefore, if anything, should have been easier to produce than repeated pictures. It is important to remember, however, that the result of interest in Experiment 1 was the bilingual effect on picture naming and that, within Experiment 1, we replicated the bilingual effect in two separate sets of materials (the repeated and the nonrepeated pictures; the comparison between repeated and nonrepeated materials was irrelevant).

Translatability effects. To test for implicit activation of Spanish during picture naming in English, we used the data from the translation test. We first divided the targets into high and low translatability, using the bilinguals' data from the post-picture-processing translation test, and defined high translatability as referring to words for which $75 \%-100 \%(M=94 \%)$ of the bilingual participants were able to translate the picture name correctly from English into Spanish, and low translatability as referring to words that fewer than $75 \%(M=49 \%$, range $=6 \%-74 \%)$ translated correctly. There were 121 highly translatable targets and 58 low-translatability targets (one item was missing from the translation test). Translatability was correlated with a number of variables that would be expected to affect both bilinguals and monolinguals in picture naming. That is, relative to low-translatability words, on average highly translatable words were higher in word form frequency [i.e., 51.82/million vs. 10.63/million; Baayen, Piepenbrock, $\&$ Gulikers, $1995 ; t(177)=3.01, S E=13.68, p<.01]$ and were names of pictures that were more familiar [i.e., 3.32 vs. 2.74; Snodgrass \& Vanderwart, 1980; $t(177)=$ $4.24, S E=0.14, p<.01]$. In addition, highly translatable words tended to be shorter in number of syllables (1.69) than were low-translatable words [1.91; although this dif- ference was not statistically robust: $t(177)=1.57, S E=$ $0.14, p=.12]$. The mean RTs and error rates for all, for difficulty-matched (see below), and for monolingual RTmatched (see below) high- and low-translatability items are shown in Table 3.

Difficulty-matched high-versus low-translatability items. To control target difficulty, we matched a subset of the high- and low-translatability targets for picture familiarity, name length, and word form frequency (in an attempt to eliminate the difficulty confound as much as possible). As in the previous items analyses, low-translatability targets that no participant in any of the three groups named correctly were excluded from all analyses (i.e., if no data were available for a particular item in one participant group, the item was excluded from both groups). The matching procedure produced 43 high- and 43 low-translatability targets that did not differ in length in syllables, word frequency, visual complexity $($ all $t \mathrm{~s}<1)$, or picture familiarity $[t(85)=1.24, S E=$ $0.16, p=.22]$. The following analyses were limited to this difficulty-matched subset of the stimulus materials. ${ }^{2}$ Mean RTs and error rates for picture-naming times were submitted to two $2 \times 2$ ANOVAs with participant type as a between-subjects variable (monolingual vs. strongEnglish bilingual) and translatability (i.e., high vs. low) as a repeated measures variable in the participants analysis and as a between groups variable in the items analysis.

There was a robust main effect of translatability, with highly translatable items producing shorter RTs $\left[F_{1}(1,53)=102.50, M S_{\mathrm{e}}=4,276.93, p<.01\right.$; $\left.F_{2}(1,168)=25.68, M S_{\mathrm{e}}=24,427.13, p<.01\right]$ and fewer errors $\left[F_{1}(1,53)=20.77, M S_{\mathrm{e}}=0.004, p<.01\right.$; $\left.F_{2}(1,168)=9.28, M S_{\mathrm{e}}=0.01, p<.01\right]$ in both bilingual and monolingual participants. In other words, despite carefully matching stimulus materials across high- and low-translatability groups, the pictures in the highly translatable group were still easier (hence, there was an effect for monolinguals; see Table 3). This finding indicates that translatability captures other variables that affect picture naming (besides frequency, name length, picture complexity, and picture familiarity).

Most interesting, and replicating the effects of translatability on TOT states (Gollan \& Acenas, 2004), bilinguals benefited relatively more than monolinguals from translatability; this interaction was significant in the analysis of participant RTs $\left[F_{1}(1,53)=4.56, M S_{\mathrm{e}}=4,276.93\right.$, $p=.04]$, although it was not robust in the analysis of item RTs $\left[F_{2}(1,168)=1.11, M S_{\mathrm{e}}=24,427.13, p=.29\right]$. The error data demonstrated a similar pattern: a trend toward an interaction in the participants analysis $\left[F_{1}(1,53)=\right.$ $\left.3.39, M S_{\mathrm{e}}=0.004, p=.07\right]$ that was not significant by item errors $\left[F_{2}(1,168)=1.60, M S_{\mathrm{e}}=0.02, p=.21\right]$. Although not robust by items, the interaction nevertheless challenges the interference account, because the direction of the effects suggests the opposite of cross-language interference. If cross-language interference affected naming times in bilinguals, the bilinguals should have shown a smaller (instead of a bigger) benefit from whatever made 
translatable stimuli easier for monolinguals, because bilinguals should also have suffered from cross-language interference for translatable stimuli. Instead, the activation of translation equivalents in the bilingual lexicon actually reduced the bilingual disadvantage.

Monolingual RT-matched high- versus lowtranslatability items. As another way of addressing the inherent confound between translatability and difficulty, we matched (as many as possible) high- $(n=23)$ and low-translatability ( $n=23)$ items for monolingual naming times. These materials also turned out to be matched for name length, picture complexity, and picture familiarity (all $t \mathrm{~s}<1$ ), and although there was a trend toward high-translatability picture names being higher in word frequency, relative to low-translatability picture names [i.e., 38/million vs. $14 /$ million; $t(44)=1.85, S E=13$, $p=.07]$, monolingual naming times and error rates for these high- and low-translatability items were virtually identical (see Table 3). After matching high- and lowtranslatability for monolingual RTs, any remaining effects of translatability in bilinguals should reflect processing mechanisms unique to bilinguals alone. Consistent with the other analyses just presented, bilinguals still named monolingual RT-matched high-translatability items more quickly $\left[1,046 \mathrm{msec} ; F_{1}(1,23)=4.44, M S_{\mathrm{e}}=8,078.59\right.$, $p=.05]$ and with fewer errors [7\% errors; $F_{1}(1,23)=$ $\left.23.04, M S_{\mathrm{e}}=0.007, p<.01\right]$, relative to the lowtranslatability items (1,100 msec; $20 \%$ errors $)$.

It might be suggested that pictures with translatable names were relatively easier for bilinguals to name simply because words that are used in both languages involve concepts that are more frequent for bilinguals. If so, the high-translatability items should also have been easier for bilinguals to classify. However, a comparison of picture classification times and error rates (these will be discussed in detail in the next section) for the same high- and low-translatability items as those included in the naming comparison revealed no significant differences in the monolinguals or the strong-English bilinguals (all $t \mathrm{~s}<$ 1.25). This suggests that translatability effects on bilingual picture naming should not be attributed to bilinguals' ability to access picture meanings.

\section{Picture Classification}

In the analysis of nonrepeated trials, mean RTs and error rates were submitted to ANOVAs with participant type as a between-subjects variable. The mean RTs and the proportion of errors in each picture classification condition are shown in Figure 2. Error rates for picture classification were so low that we carried out statistical analysis only on the RT data. In stark contrast to the results of the picture-naming task, in picture classification there were no main effects of participant type. Strong-English bilinguals classified nonrepeated pictures as quickly as did monolinguals (both $F_{\mathrm{s}}<1$ ).

In the analysis of repeated trials, mean RTs and error rates were submitted to two $2 \times 2$ ANOVAs with participant type as a between-subjects variable (monolingual vs. strong-English bilingual) and repetition as a repeated mea-

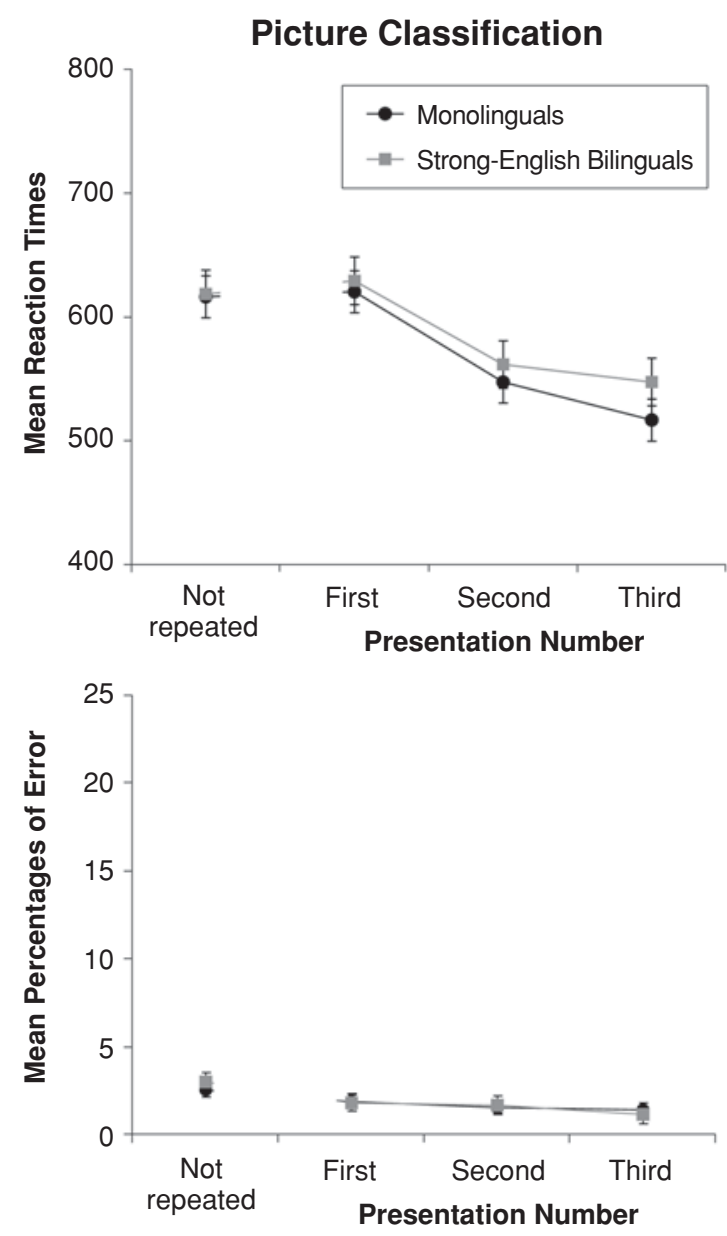

Figure 2. Mean picture classification reaction times (top panel; in milliseconds) and error rates (bottom panel) for nonrepeated $(n=120)$ and repeated $(n=60)$ pictures in monolinguals and strong-English bilinguals in Experiment 1. Error bars show the standard error of the mean for each participant group.

sures variable (i.e., first, second, and third presentations). As was reported in the results of the picture-naming task, there were robust main effects of repetition in the picture classification data $\left[F_{1}(1,53)=158.97, M S_{\mathrm{e}}=1,465.63\right.$, $\left.p<.01 ; F_{2}(1,118)=130.75, M S_{\mathrm{e}}=4,437.37, p<.01\right]$. In addition, strong-English bilinguals and monolinguals appeared to benefit similarly from repetition, as is indicated by the lack of an interaction between participant type and repetition $\left[F_{1}(1,53)=2.23, M S_{\mathrm{e}}=1,465.63\right.$, $\left.p=.14 ; F_{2}(1,118)=1.58, M S_{\mathrm{e}}=4,437.37, p=.21\right]$. Another similarity between the picture classification data and the picture-naming data is that the bulk of the repetition effect appeared to occur between the first and the second presentations of a picture (see Figures 1 and 2).

\section{EXPERIMENT 2 Naming Pictures Five Times}

In Experiment 1, the effect of bilingualism on picture naming was resistant to two repetitions. This finding does 
not support the idea that bilinguals differ from monolinguals primarily in the sense that bilinguals use their English relatively less than do monolinguals. However, the weaker links hypothesis is not sufficiently specific to allow an a priori prediction about how many experimental repetitions would be needed for a particular group of bilinguals to become equal to monolinguals. To determine whether an increased number of repetitions would significantly attenuate the bilingual disadvantage in picture naming, we doubled the number of repetitions from two in Experiment 1 to four in Experiment 2.

\section{Method}

\section{Participants}

We recruited 36 English-speaking monolinguals and 36 SpanishEnglish bilinguals from the same population as that in Experiment 1 to participate in the experiment for course credit. As in Experiment 1, the majority of the bilinguals reported being English-dominant or speaking both languages equally well $(n=29)$. In Experiment 2, our primary goal was to evaluate repetition effects (and not, as in Experiment 1, to determine whether strong-English bilinguals name pictures more slowly than do monolinguals); thus, in the Results section, we will report analyses including all 36 bilinguals (and will note one small difference that we found when limiting the analysis to strong-English bilinguals). There were 8 bilinguals who reported both their English and their Spanish to be as good as that of a native speaker (i.e., a 7), 9 bilinguals who rated themselves as nativelike in English and very good (i.e., a 6) in Spanish, 2 bilinguals who rated themselves as nativelike in English and good (i.e., a 5) in Spanish, 1 bilingual who rated himself as nativelike in English and functional (i.e., a 4) in Spanish, 2 bilinguals who rated themselves as very good in both languages, 3 bilinguals who rated themselves as good in both languages, and 4 bilinguals who rated themselves as very good in English and good in Spanish. Of the 7 reportedly Spanishdominant bilinguals, 3 rated themselves as nativelike in Spanish and very good in English, 1 rated herself as nativelike in Spanish and good in English, 2 rated themselves as nativelike in Spanish and functional in English, and 1 bilingual rated himself as very good in Spanish and good in English.

Table 1 shows the average participant characteristics obtained from the language questionnaire. Monolinguals and bilinguals did not differ significantly in average age $(t<1)$. In contrast, and as in Experiment 1, on average, monolinguals rated themselves as better English speakers than did bilinguals, bilinguals reported using a language other than English on a daily basis more often than did monolinguals, learned English at an older age, learned to speak two languages at a younger age, and rated themselves as having a higher level of proficiency in a language other than English. All of these differences were tested in two-tailed $t$ tests and were significant at the $p<.01$ level.

\section{Materials}

We chose 60 black-and-white line-drawn pictures from Snodgrass and Vanderwart (1980) and from other databases in the Language Production Laboratory at the University of California at San Diego. Picture names averaged $37.5(S D=87.8)$ in word frequency per million (Baayen et al., 1995) and were $1.9(S D=0.8)$ syllables long. As in Experiment 1, pictures with cognate names (e.g., elephant and elefante) were included to the extent that they occurred in the picture database (i.e., $n=21$ ). An additional 5 pictures were used as practice items. The set of 60 target pictures was organized into 15 different random orders, and these were divided into three lists with five randomly ordered presentations in each list (12 bilinguals and 12 monolinguals named pictures in each of these three lists). In each list, the full set of 60 pictures was presented before any
}

of the items were repeated, and this restriction applied to subsequent repetitions as well (e.g., all the pictures were presented twice before any picture was presented for a third time, etc.). In addition, in all three lists, the same picture was never presented on consecutive trials. The task began with 25 practice trials with 5 practice pictures that were presented five times, and the 300 (i.e., 60 pictures $\times 5$ presentations) target trials followed.

\section{Procedure}

The participants were tested individually in sessions lasting 1$1.5 \mathrm{~h}$ in a small testing room with the experimenter present. The participants were instructed to name the pictures as quickly as possible without making mistakes. The pictures were presented using PsyScope 1.2.3 (Cohen et al., 1993) on Macintosh computers with 17 -in. color monitors. Before each picture, a plus sign appeared at the center of the screen for $500 \mathrm{msec}$ and was immediately replaced by the picture. Each picture remained on the screen until the participant responded or until $4 \mathrm{sec}$ had elapsed, and there was a 500-msec interval between the response and the beginning of the next trial. The participants were given two rest periods (one after the 100th and one after the 200th pictures had been presented). The participants were instructed to take a brief rest and then to press the space bar to continue. The participants named pictures in English and were encouraged to guess if they were unsure of the target name and to say "don't know" or "pass" if they could not guess. RTs were recorded with headset microphones connected to cassette recorders and PsyScope response boxes. Picture-naming and voice key accuracy was monitored by the experimenter online and was double-checked prior to data analysis, using the audiocassettes. Picture-naming RTs were recorded by the response box. After completing the computerpresented portion of the experiment, the participants were given a language and medical history questionnaire in order to assess their language background and to exclude participants with risk factors for cognitive impairment.

\section{Results and Discussion}

Mean and standard deviations of RTs for correct responses and error rates were calculated separately for each participant in the bilingual and the monolingual groups. The dominant response for the picture of a hippopotamus was changed because most of the participants used hippo. RTs for nondominant but acceptable naming responses (e.g., necktie instead of tie) were not included in the analysis of RTs but were not considered to be errors. All RTs greater than two standard deviations of each participant's mean (of dominant responses only) were eliminated. This procedure led to trimming of $4.5 \%$ of monolingual RTs and $4.6 \%$ of bilingual RTs.

Mean RTs and error rates were submitted to a $2 \times 5$ ANOVA with participant type as a between-subjects variable (monolingual and bilingual), and repetition as a repeated measures variable (i.e., first-fifth presentations). Item analyses were carried out only once (and including all the items in all repetitions) because there were no missing data points (i.e., pictures that only monolinguals named correctly on the first presentation). Main effects of repetition were highly robust, with shorter naming times $\left[F_{1}(1,70)=183.05, M S_{\mathrm{e}}=3,632, p<\right.$ $\left..01 ; F_{2}(1,118)=352.98, M S_{\mathrm{e}}=4,193, p<.01\right]$ and fewer errors $\left[F_{1}(1,70)=52.31, M S_{\mathrm{e}}=0.001, p<.01\right.$; $\left.F_{2}(1,118)=44.66, M S_{\mathrm{e}}=0.002, p<.01\right]$ on successive repetitions. There was a main effect of participant type, 
with bilinguals naming pictures more slowly and with more errors than did monolinguals, that was marginally significant in the analysis of participant $\mathrm{RTs}\left[F_{1}(1,70)=\right.$ $\left.3.11, M S_{\mathrm{e}}=49,996, p=.08\right]$ and significant by item RTs $\left[F_{2}(1,118)=13.54, M S_{\mathrm{e}}=18,140, p<.01\right]$ and in the errors analyses $\left[F_{1}(1,70)=19.36, M S_{\mathrm{e}}=0.02, p<.01\right.$; $\left.F_{2}(1,118)=8.01, M S_{\mathrm{e}}=0.08, p<.01\right]$.

Most important, there was an interaction between participant type and repetition such that bilinguals benefited more from repetition than did monolinguals. The interaction was significant in the analysis of the RT data $\left[F_{1}(1,70)=6.36\right.$, $M S_{\mathrm{e}}=3,633, p=.01 ; F_{2}(1,118)=11.71, M S_{\mathrm{e}}=4,193$, $p<.01]$ and in the analysis of the error data $\left[F_{1}(1,70)=\right.$ 6.62, $M S_{\mathrm{e}}=0.001, p=.01 ; F_{2}(1,118)=4.58, M S_{\mathrm{e}}=$ $0.002, p=.03]$. This result is shown in Figure 3. This interaction was also marginally significant when the analysis was limited to strong-English bilinguals only (i.e., excluding the 8 Spanish-dominant bilinguals) in both the RT data $\left[F_{1}(1,63)=2.51, M S_{\mathrm{e}}=2,871, p=.12\right]$ and the error data $\left[F_{1}(1,63)=4.04, M S_{\mathrm{e}}=0.001, p=.05\right]$, suggesting that the interaction was not dependent on production in the less dominant language.

The results of Experiment 2 were similar to those in Experiment 1 in a number of ways. First, as can be seen by comparing Figures 1 and 3, in both experiments, repetition effects were largest between the first and the second presentations (as was noted above, the same was true of picture classification in Experiment 1). Critically, Experiment 2 was designed to test the hypothesis that three repetitions were insufficient to eliminate the bilingual disadvantage for picture naming in Experiment 1. Consistent with this hypothesis, in Experiment 2 the bilingual disadvantage for picture-naming times was still marginally significant by participant RTs after three presentations $[t(70)=1.68, S E=25.09, p=.10]$, but by the fifth presentation, the bilinguals in Experiment 2 named pictures as quickly as did the monolinguals $(t<$ 1). Although the bilingual disadvantage in the error data remained robust on the fifth presentation $[t(70)=3.83$, $S E=0.01, p<.01]$, the resistance of errors to repetitions may be because some of the errors included pictures that the participants did not know or for which they had forgotten their names. Picture repetition is unlikely to remind participants of forgotten names and certainly would not teach them names that they did not know.

The fact that bilingual naming times benefited more from repeated presentation than did monolingual naming times and that the bilinguals named pictures as quickly as

\section{Picture Naming}
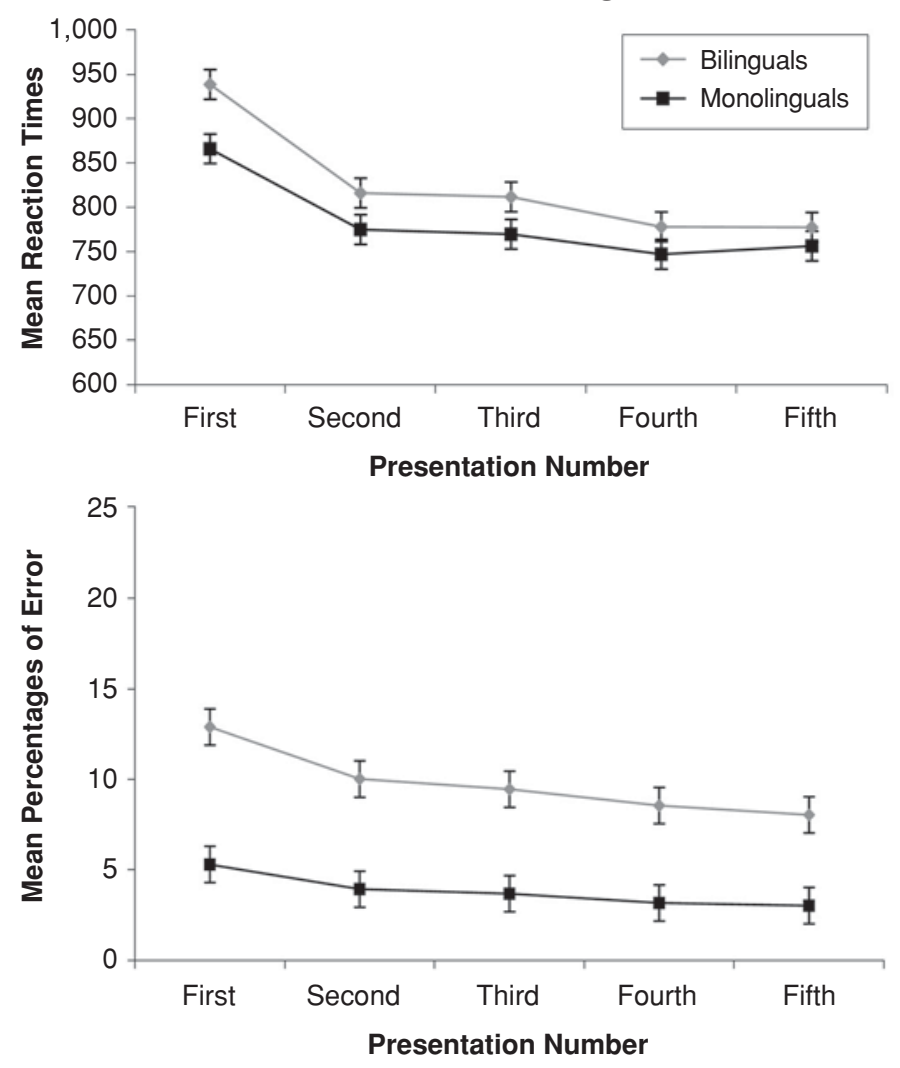

Figure 3. Mean picture naming reaction times (top panel; in milliseconds) and error rates (bottom panel) for monolinguals and bilinguals in Experiment 2. Error bars show the standard error of the mean for each participant group. 
did monolinguals on the fourth repetition confirms two predictions of the weaker links account.

\section{GENERAL DISCUSSION}

In this study, we compared bilinguals who learned both Spanish and English at an early age with age-matched English-speaking monolinguals on picture classification and picture naming in English. Our primary goal was to determine whether strong-English bilinguals - that is, bilinguals who reported that English was their best language or who reported equal ability in both languages - would nevertheless demonstrate evidence of their bilingual language history. The results seem to provide a clear answer to this question. On the picture-naming task, strongEnglish bilinguals named pictures more slowly and with more errors. Furthermore, in the context of robust repetition effects for both bilinguals and monolinguals (i.e., shorter RTs and fewer errors on second and third presentations of pictures), the bilinguals still named pictures more slowly on the third presentation of the picture in both Experiments 1 and 2. In stark contrast to the robust group differences for picture naming, the same bilinguals classified the pictures as human made vs. natural just as quickly as monolinguals (and both participant groups made very few errors on this task).

The presence of robust differences in picture naming in the absence of any differences in picture classification constrains accounts of the effect of bilingualism on picture naming. First, because bilinguals were not slower on all tasks, it appears that bilingualism does not lead to generalized differences. Instead, differences may be obtained only on tasks that involve accessing lexical representations. The absence of a difference between groups in picture classification also suggests that the locus of the bilingual effect arises after semantic processing during the retrieval of language-specific lexical representations for production. The results are also consistent with the assumptions that bilinguals have a single semantic store that is accessed by both languages, that bilinguals and monolinguals do not differ at the semantic level, and that knowledge of two languages does not alter conceptual representations.

Equivalent performance on picture classification is a null finding, however, and as such it leaves open the possibility that bilinguals and monolinguals may have carried out the task in different ways or that semantic memory does differ (in at least some ways) across groups. At least in principle, it is possible that there were two (or more) different but equally efficient ways of classifying pictures. The absence of differences between groups leaves open the possibility that bilinguals and monolinguals used different strategies that could not be detected by the task we used (i.e., it is impossible to prove a lack of differences between groups). ${ }^{3}$ Nevertheless, it is important to note that the classification task demonstrated highly robust repetition effects and, thus, was sensitive to at least one manipulation. In addition, because the same pictures were used in both tasks (with counterbalanced presentation, such that no individual participant named and classified the same picture in both tasks), the lack of difference between groups in picture classification cannot be attributed simply to a materials effect (e.g., it cannot be that the pictures used in semantic classification were simply easier).

The semantic classification task was considerably easier than the naming task (as evidenced by shorter RTs in classification; see Figures 1 and 3), and as such, it may seem that bilinguals simply perform worse on more difficult tasks. However, an argument against this possibility comes from a recent study on proper name retrieval, which is especially difficult for monolinguals. In that study, bilinguals and monolinguals had the same rate of TOTs for proper names, even though the basic effect of bilingualism (in this case, a higher TOT rate) was still present for the relatively easier task, which was producing names of pictured objects and other non-proper-name targets (Gollan, Bonanni, \& Montoya, 2005).

\section{The Locus of the Bilingual Effect on Picture Naming}

Cross-language interference. A secondary goal of the present investigation was to further constrain accounts of the difference between participant groups; that is, we addressed the question of why bilinguals, even strong-English bilinguals, ${ }^{4}$ are slower and more error prone, relative to their monolingual peers, in picture naming? Given the considerable evidence in the literature on bilingualism that both languages are always active (i.e., that it is impossible to "turn one language off"), a common assumption is that this dual activation inevitably leads to interference. On the assumption that cross-language interference would be possible only if bilinguals could produce the word in both languages, we then divided picture names into those that most bilinguals knew in both languages (high-translatability targets) and those that most bilinguals knew in English only (low-translatability targets) and predicted that differences between participant groups should be greater on high-translatability targets.

The results suggested that translations, in fact, cued each other; bilinguals named high-translatability targets more quickly and with fewer errors. Although high-translatability targets were also easier for monolinguals to name, bilinguals appeared to benefit more from translatability (there was an interaction). If translation equivalents competed for selection, there should have been an interaction in the opposite direction (see Table 3), because bilinguals should have benefited from whatever made translatable items easier to name for monolinguals but, also, should have been slowed by cross-language interference between translatable names. In addition, even after matching highand low-translatability words for monolingual RTs, bilinguals still demonstrated shorter naming times for pictures with translatable names. Finally, the pictures that revealed robust translatability effects on picture naming showed no effects of translatability on classification responses. This provides evidence against the possibility that pictures with translatable names involved concepts that were more familiar to bilinguals. Instead, it appears that translatability reflected a property of the picture names; knowledge 
Table 3

Mean Reaction Times (RTs, in Milliseconds) and Error Rates (With Standard Deviations) for All, Difficulty-Matched, and Monolingual RT-Matched High- and Low-Translatability Items in Experiment 1

\begin{tabular}{|c|c|c|c|c|c|c|c|c|c|}
\hline \multirow[b]{3}{*}{ Materials } & \multirow{3}{*}{$\begin{array}{c}\text { Translatability } \\
\text { Type }\end{array}$} & \multicolumn{4}{|c|}{ Bilingual } & \multicolumn{4}{|c|}{ Monolingual } \\
\hline & & \multicolumn{2}{|c|}{ RTs } & \multicolumn{2}{|c|}{$\%$ Errors } & \multicolumn{2}{|c|}{ RTs } & \multicolumn{2}{|c|}{$\%$ Errors } \\
\hline & & $M$ & $S D$ & $M$ & $S D$ & $M$ & $S D$ & $M$ & $S D$ \\
\hline \multirow[t]{2}{*}{ All } & $\operatorname{High}(n=121)$ & 943 & 103 & 4.6 & 2.8 & 874 & 134 & 5.3 & 3.1 \\
\hline & Low $(n=58)$ & 1,111 & 145 & 18.9 & 7.9 & 991 & 140 & 12.9 & 9.1 \\
\hline \multirow[t]{2}{*}{ Difficulty matched } & $\operatorname{High}(n=43)$ & 957 & 116 & 5.1 & 4.7 & 876 & 125 & 5.7 & 5.8 \\
\hline & Low $(n=43)$ & 1,111 & 161 & 12.8 & 8.8 & 976 & 144 & 9.0 & 6.9 \\
\hline \multirow[t]{2}{*}{ Monolingual RT matched } & $\operatorname{High}(n=23)$ & 1,046 & 126 & 7.1 & 7.4 & 993 & 168 & 12.6 & 8.2 \\
\hline & Low $(n=23)$ & 1,100 & 145 & 19.4 & 33.3 & 995 & 136 & 11.4 & 12.0 \\
\hline
\end{tabular}

of a Spanish translation may have made the English word more accessible to bilinguals (instead of less accessible, as predicted by the interference account).

These results replicated and extended a similar finding on TOT rates in bilinguals and monolinguals (Gollan \& Acenas, 2004) and provided evidence that translatability influences failed and intact lexical retrievals in similar ways. These results also suggest that dual-language activation is present even when translations are not explicitly presented, as in previous studies in which bilinguals named pictures more quickly when the pictures were overtly presented with the translation words as distractors (Costa \& Caramazza, 1999; Costa et al., 1999). The presence of an implicit effect of dual-language activation is an important consideration, because explicitly presenting words in both languages (as in Costa et al., 1999) forces both languages to be active. Implicit effects provide more convincing evidence that both languages are active during single-language tasks.

To explain both overt and implicit translatability facilitation effects, we propose that the target receives extra activation from its translation equivalent (see also Costa et al., 1999). Because the translations were never overtly presented in the present study, the added activation would arise when pictures automatically activated lexical nodes in both languages (even though the task was naming in English only). For high-translatability targets, each picture stimulus would activate two lexical representations (one in Spanish and one in English), whereas for lowtranslatability targets, the picture could activate only the target English lexical representation. With two lexical representations active but not competing for selection, translation equivalents could, instead, be directly connected via facilitatory links. Alternatively, facilitation could arise through support to the semantic system. By this view, the lexical representation in the nontarget language (Spanish, in this case) would serve to maintain more active the semantic nodes needed to select the target English lexical representation.

Translatability facilitation effects argue against crosslanguage interference; however, it is important to note that the majority of the participants in the present study were English-dominant bilinguals, were immersed in an English-speaking environment, and named the pictures in their dominant language. These conditions are maximally weighted against detecting cross-language interference (the conditions under which it was, therefore, also most surprising to obtain a bilingual disadvantage). In addition, interference may be more likely in tasks that involve frequent language switching (Hernandez \& Kohnert, 1999; Kohnert, Bates, \& Hernandez, 1999; Kroll \& Peck, 1998; Meuter \& Allport, 1999; Thomas \& Allport, 2000; but see Costa et al., 1999).

Weaker links. Another mechanism that we considered as an explanation for the bilingual disadvantage is that, relative to monolinguals, bilinguals have weaker links from semantic representations to lexical representations in both languages (Gollan \& Acenas, 2004; Gollan et al., 2002; Gollan \& Silverberg, 2001; for similar ideas, see Ransdell \& Fischler, 1987; Mägiste, 1979). In general terms, this view stipulates that bilinguals are essentially less proficient or fluent than monolinguals. One way to elaborate the weaker links hypothesis beyond general stipulations about proficiency and to provide a cognitive mechanism as the basis for bilinguals' relatively reduced ability to access word forms is to rely on an analogy with word frequency. Specifically, bilingual patterns of language use may influence word forms in the same way that frequency influences word forms in monolinguals. By this view, bilinguals' relatively decreased ability to activate lexical representations (even in the dominant language) arises because bilinguals split their time using word forms in two different languages and, therefore, spend less time strengthening the connections particular to each language - even in the dominant language - relative to monolinguals. To test the predictions of the weaker links account, we presented some of the pictures three times in Experiment 1 and all of the pictures five times in Experiment 2 and predicted that, with sufficient practice, the difference between bilinguals and monolinguals should disappear.

Unlike the interference account, the weaker links account assumes an indirect effect of bilingualism on fluency and resembles proposals that lexical representations in the less dominant language are not as accessible as representations in the dominant language (e.g., Francis, Augustini, \& Sáenz, 2003; Hermans et al., 1998). The weaker links account assumes that overall, bilinguals and monolinguals spend roughly the same amount of time speaking (i.e., the deficit should not be present in a 
bilingual person who speaks twice as much as the average monolingual) and that bilinguals and monolinguals require roughly the same absolute number of exposures to word forms to be able to produce them efficiently. In other words, bilinguals are different primarily in that, over time, they have retrieved word forms particular to each language less often, relative to monolinguals.

The present data supported the weaker links account in two ways. First, after four presentations, bilinguals named pictures as quickly as did monolinguals. This result is important because it suggests that if bilinguals spoke their dominant language as often as monolinguals spoke their only language, there would be no disadvantage associated with bilingualism. Second, given sufficient repetitions (i.e., in Experiment 2, but not in Experiment 1), bilinguals benefited more from repetition than did monolinguals. This invites an analogy between word frequency and bilingualism. Like bilinguals relative to monolinguals, low-frequency words benefited more from repetition, relative to high-frequency words (Griffin \& Bock, 1998). As such, being bilingual may be analogous to (on average) having more word forms at lower levels of resting activation, relative to monolinguals. Using an activation metaphor (note that the same prediction would be derived from virtually any model that explains how increased use reduces access time), the difference between bilinguals and monolinguals disappears with repetition because, on average, lexical representations in bilinguals are further from ceiling levels of activation at baseline, relative to lexical representations in monolinguals.

It is important to note that the presence or absence of a greater repetition effect on bilinguals supports the weaker links account only to the extent that repetition influences lexical access in the same way as does natural exposure. Murray and Forster (2004) recently challenged this assumption and demonstrated that repetition effects in word recognition are obtained only when some nonrepeated items are intermixed in the stimuli. They argued that a small number of repetitions should have no effect on lexical access times and that such repetition effects, instead, reflect changes in familiarity with the stimulus induced by the episodic memory trace of the recent encounter with it (i.e., a process that should not be different in bilinguals and monolinguals; see also Feustel, Shiffrin, \& Salasoo, 1983; Forster \& Davis, 1984). That said, however, the fact that we obtained significant repetition effects in picture naming even when all of the items were repeated (see Experiment 2) suggests that different mechanisms supported the repetition effects reported in this study.

Before concluding, we will point out an aspect of the picture-naming data that we think is compelling. When bilingual picture-naming times on the third presentation are compared with monolingual picture-naming times on the second presentation (i.e., third for bilinguals vs. second for monolinguals; see Figures 1 and 3), there was no difference between strong-English bilinguals and monolinguals in either Experiment 1 or $2(t<1)$. This comparison gives both bilinguals and monolinguals one opportunity to become familiar with the picture (the first presentation) but allows bilinguals to "catch up" with monolinguals between the second and the third presentations. In other words, giving bilinguals just one additional presentation (relative to monolinguals) was sufficient to make up differences in language use between bilinguals and monolinguals and to reduce the bilingual effect on picture naming to the point that it was no longer significant. As with the absence of a difference between bilinguals and monolinguals for picture classification, this suggests that bilinguals are different from monolinguals in subtle ways that may attenuate quickly. It also suggests that in natural conversations, in which many words are repeated, bilinguals and monolinguals would be more similar than they are different.

To summarize, we propose that when bilinguals name pictures in their dominant language, they differ from monolinguals primarily in the degree of experience that they have had with picture names particular to that language. It is worth noting, however, that the weaker links and interference accounts are not mutually exclusive. The interference account does not predict that the bilingual effect on picture naming should attenuate with repetition, but it could accommodate this finding, or a null or even the opposite finding. As such, attenuation of the bilingual effect with repetition supports the weaker links hypothesis and constrains, but does not necessarily challenge, the interference account. Similarly, the translatability effects we obtained challenge the interference account and constrain, but do not challenge or support, the weaker links hypothesis. Ultimately, both hypotheses together may best explain bilingual performance in different circumstances.

\section{REFERENCES}

BaAyen, R. H., Piepenbrock, R., \& Gulikers, L. (1995). The CELEX lexical database [CD-ROM]. Philadelphia: University of Pennsylvania, Linguistic Data Consortium.

BiAlystoK, E. (2005). Consequences of bilingualism for cognitive development. In J. F. Kroll \& A. M. B. de Groot (Eds.), Handbook of bilingualism: Psycholinguistic approaches (pp. 417-432). New York: Oxford University Press.

Bijeljac-Babic, R., Biardeau, A., \& Grainger, J. (1997). Masked orthographic priming in bilingual word recognition. Memory \& Cognition, 25, 447-457.

Brown, A. (1991). A review of the tip-of-the-tongue experience. Psychological Bulletin, 109, 204-223.

Brown, R., \& MCNeILl, D. (1966). The "tip of the tongue" phenomenon. Journal of Verbal Learning \& Verbal Behavior, 5, 325-337.

Cohen, J., MacWhinney, B., Flatt, M., \& Provost, J. (1993). PsyScope: An interactive graphic system for designing and controlling experiments in the psychology laboratory using Macintosh computers. Behavior Research Methods, Instruments, \& Computers, 25, 257-271.

Costa, A., \& Caramazza, A. (1999). Is lexical selection in bilingual speech production language-specific? Further evidence from SpanishEnglish and English-Spanish bilinguals. Bilingualism: Language \& Cognition, 2, 231-244.

Costa, A., Caramazza, A., \& Sebastian-Galles, N. (2000). The cognate facilitation effect: Implications for models of lexical access. Journal of Experimental Psychology: Learning, Memory, \& Cognition, 26, 1283-1296.

Costa, A., Miozzo, M., \& Caramazza, A. (1999). Lexical selection in bilinguals: Do words in the bilingual's two lexicons compete for selection? Journal of Memory \& Language, 41, 365-397.

Costa, A., \& Santesteban, M. (2004). Lexical access in bilingual speech production: Evidence from language switching in highly pro- 
ficient bilinguals and L2 learners. Journal of Memory \& Language, 50, 491-511.

De Groot, A. M. B., \& NAS, G. L. (1991). Lexical representation of cognates and noncognates in compound bilinguals. Journal of Memory \& Language, 30, 90-123.

Feustel, T. C., Shiffrin, R. M., \& Salasoo, A. (1983). Episodic and lexical contributions to the repetition effect in word identification. Journal of Experimental Psychology: General, 112, 309-346.

Forster, K. I., \& DaVIS, C. (1984). Repetition priming and frequency attenuation in lexical access. Journal of Experimental Psychology: Learning, Memory, \& Cognition, 10, 680-698.

FRANCIS, W. S. (1999a). Analogical transfer of problem solutions within and between languages in Spanish-English bilinguals. Journal of Memory \& Language, 40, 301-329.

FrancIS, W. S. (1999b). Cognitive integration of language and memory in bilinguals: Semantic representation. Psychological Bulletin, 125, 193-222.

FrancIs, W. S. (2005). Bilingual semantic and conceptual representation. In J. F. Kroll \& A. M. B. de Groot (Eds.), Handbook of bilingualism: Psycholinguistic approaches (pp. 251-267). New York: Oxford University Press.

Francis, W. S., Augustini, B. K., \& Sáenz, S. P. (2003). Repetition priming in picture naming and translation depends on shared processes and their difficulty: Evidence from Spanish-English bilinguals. Journal of Experimental Psychology: Learning, Memory, \& Cognition, 29, 1283-1297.

Gollan, T. H., \& Acenas, L. A. (2004). What is a TOT? Cognate and translation effects on tip-of-the-tongue states in Spanish-English and Tagalog-English bilinguals. Journal of Experimental Psychology: Learning, Memory, \& Cognition, 30, 246-269.

Gollan, T. H., Bonanni, M. P., \& Montoya, R. I. (2005). Proper names get stuck on bilingual and monolingual speakers' tip of the tongue equally often. Neuropsychology, 19, 278-287.

Gollan, T. H., \& Kroll, J. F. (2001). Bilingual lexical access. In B. Rapp (Ed.), A handbook of cognitive neuropsychology: What deficits reveal about the human mind/brain (pp. 321-345). Philadelphia: Psychology Press.

Gollan, T. H., Montoya, R. I., \& Werner, G. (2002). Semantic and letter fluency in Spanish-English bilinguals. Neuropsychology, 16, 562-576.

Gollan, T. H., \& SilverberG, N. B. (2001). Tip-of-the-tongue states in Hebrew-English bilinguals. Bilingualism: Language \& Cognition, 4, 63-84.

Goodglass, H., \& Kaplan, E. (1987). The assessment of aphasia and related disorders (2nd ed.). Philadelphia: Lea \& Febiger.

GrifFIn, Z. M., \& BocK, K. (1998). Constraint, word frequency, and the relationship between lexical processing levels in spoken word production. Journal of Memory \& Language, 38, 313-338.

Grosjean, F. (1997). Processing mixed language: Issues, findings, and models. In A. M. B. de Groot \& J. F. Kroll (Eds.), Tutorials in bilingualism: Psycholinguistic perspectives (pp. 225-254). Mahwah, NJ: Erlbaum.

Harris, R. J., \& McGhee Nelson, E. M. (1992). Bilingualism: Not the exception any more. In R. J. Harris (Ed.), Cognitive processing in bilinguals (pp. 3-14). Amsterdam: North-Holland.

Hermans, D., Bongaerts, T., DE Bot, K., \& Schreuder, R. (1998) Producing words in a foreign language: Can speakers prevent interference from their first language? Bilingualism: Language \& Cognition, 1, 213-229.

HernANDEZ, A. E., \& KoHNERT, K. J. (1999). Aging and language switching in bilinguals. Aging, Neuropsychology, \& Cognition, 6, 69-83.

JARED, D., \& Kroll, J. F. (2001). Do bilinguals activate phonological representations in one or both of their languages when naming words? Journal of Memory \& Language, 44, 2-31.

Keatley, C. W. (1992). History of bilingualism research in cognitive psychology. In R. J. Harris (Ed.), Cognitive processing in bilinguals (pp. 15-49). Amsterdam: North-Holland.

Keatley, C. W., Spinks, J. A., \& de Gelder, B. (1994). Asymmetrical cross-language priming effects. Memory \& Cognition, 22, 70-84.

Kohnert, K. J., Bates, E., \& Hernandez, A. E. (1999). Balancing bilinguals: Lexical-semantic production and cognitive processing in children learning Spanish and English. Journal of Speech, Language, \& Hearing Research, 42, 1400-1413.
Kohnert, K. J., Hernandez, A. E., \& Bates, E. (1998). Bilingual performance on the Boston Naming Test: Preliminary norms in Spanish and English. Brain \& Language, 65, 422-440.

KROLL, J. F. (1993). Accessing conceptual representation for words in a second language. In R. Schreuder \& B. Weltens (Eds.), The bilingual lexicon (pp. 53-81). Amsterdam: Benjamins.

Kroll, J. F., \& DE Groot, A. M. B. (1997). Lexical and conceptual memory in the bilingual: Mapping form to meaning in two languages. In A. M. B. de Groot \& J. F. Kroll (Eds.), Tutorials in bilingualism: Psycholinguistic perspectives (pp. 169-199). Mahwah, NJ: Erlbaum.

Kroll, J. F., \& DiJKstra, A. (2002). The bilingual lexicon. In R. Kaplan (Ed.), Handbook of applied linguistics (pp. 301-321). Oxford: Oxford University Press.

Kroll, J. F., \& Peck, A. (1998, April). Competing activation across a bilingual's two languages: Evidence from picture naming. Paper presented at the 43rd Annual Meeting of the International Linguistic Association, New York.

Kroll, J. F., \& Stewart, E. (1994). Category interference in translation and picture naming: Evidence for asymmetric connections between bilingual memory representations. Journal of Memory \& Language, 33, 149-174.

Lee, M. W., \& Williams, J. N. (2001). Lexical access in spoken word production by bilinguals: Evidence from the semantic competitor priming paradigm. Bilingualism: Language \& Cognition, 4, 233-248.

LeVelt, W. J. M., Roelofs, A., \& Meyer, A. S. (1999). A theory of lexical access in speech production. Behavioral \& Brain Sciences, 22, 1-75.

MäGISTE, E. (1979). The competing language systems of the multilingual: A developmental study of decoding and encoding processes. Journal of Verbal Learning \& Verbal Behavior, 18, 79-89.

Meuter, R. F. I., \& Allport, A. (1999). Bilingual language switching in naming: Asymmetrical costs of language selection. Journal of Memory \& Language, 40, 25-40.

Michael, E., \& Gollan, T. H. (2005). Being and becoming bilingual: Individual differences and consequences for language production. In J. F. Kroll \& A. M. B. de Groot (Eds.), Handbook of bilingualism: Psycholinguistic approaches (pp. 389-407). New York: Oxford University Press.

MurraY, W. S., \& Forster, K. I. (2004). Serial mechanisms in lexical access: The rank hypothesis. Psychological Review, 111, 721-756.

PavlenKo, A. (1999). New approaches to concepts in bilingual memory. Bilingualism: Language \& Cognition, 2, 209-230.

Ransdell, S., Arecco, M. R., \& Levy, C. M. (2001). Bilingual longterm working memory: The effects of working memory loads on writing quality and fluency. Applied Psycholinguistics, 22, 113-128.

Ransdell, S. E., \& Fischler, I. (1987). Memory in a monolingual mode: When are bilinguals at a disadvantage? Journal of Memory \& Language, 26, 392-405.

Roberts, P. M., Garcia, L. J., Desrochers, A., \& Hernandez, D. (2002). English performance of proficient bilingual adults on the Boston Naming Test. Aphasiology, 16, 635-645.

Rosselli, M., Ardila, A., Araujo, K., Weekes, V. A., Caracciolo, V., Padilla, M., \& Ostrosky-Solis, F. (2000). Verbal fluency and repetition skills in healthy older Spanish-English bilinguals. Applied Neuropsychology, 7, 17-24.

Sмiтн, M. C. (1997). How do bilinguals access lexical information? In A. M. B. de Groot \& J. F. Kroll (Eds.), Tutorials in bilingualism: Psycholinguistic perspectives (pp. 145-168). Mahwah, NJ: Erlbaum. SnOdgrass, J. G., \& VANDERWART, M. (1980). A standardized set of 260 pictures: Norms for name agreement, image agreement, familiarity, and visual complexity. Journal of Experimental Psychology: Human Learning \& Verbal Behavior, 23, 67-83.

Thomas, M. S. C., \& Allport, A. (2000). Language switching costs in bilingual visual word recognition. Journal of Memory \& Language, 43, 44-66.

TокошісZ, N. (2000). Meaning representation within and across languages. Unpublished doctoral dissertation, Pennsylvania State University.

Tzelgov, J., HeniK, A., \& Leiser, D. (1990). Controlling Stroop interference: Evidence from a bilingual task. Journal of Experimental Psychology: Learning, Memory, \& Cognition, 16, 760-771.

van Hell, J. G., \& DE Groot, A. M. B. (1998). Conceptual representation in bilingual memory: Effects of concreteness and cognate status in word association. Bilingualism: Language \& Cognition, 1, 193-211. 
van Heuven, W. J. B., Dijkstra, T., \& Grainger, J. (1998). Orthographic neighborhood effects in bilingual word recognition. Journal of Memory \& Language, 39, 458-483.

Viswanathan, M., \& Childers, T. L. (2003). An enquiry into the process of categorization of pictures and words. Perceptual \& Motor Skills, 96, 267-287.

WheEldon, L. R., \& Monsell, S. (1994). Inhibition of spoken word production by priming a semantic competitor. Journal of Memory \& Language, 33, 332-356.

\section{NOTES}

1. We use the terms meaning, semantic, and conceptual to refer to nonlinguistic representations. For a discussion of the distinction between semantic and conceptual representations in bilingualism, see Pavlenko, 1999.

2. Prior research showed that bilinguals named pictures with cognate names (e.g., giraffe, which is jirafa in Spanish) more quickly than pictures with noncognate names (Costa, Caramazza, \& Sebastian-Galles, 2000); thus, we considered whether cognate status influenced the results. There were seven pictures with cognate names in the low-translatability group and seven in the high-translatability group, but the direction and magnitude of the effects reported below did not change substantially when these items were excluded, and thus we report the analysis that included all items.

3. Some preliminary results from an ongoing study by the first author (T.H.G.), using the same participant groups, showed a bilingual disadvantage relative to monolinguals on a more difficult version of the semantic classification task. Participants classified pictures in a go-no-go task as fruits (with one keypress), as vegetables (with a different keypress), or as neither (by not responding and waiting for the next picture to appear). We hypothesize that when classification is very difficult, participants may rely on language to carry out the task and that this strategy would produce a difference between bilinguals and monolinguals. A challenge for this proposal is that pictures are often categorized more quickly than words (for a recent review, see Viswanathan \& Childers, 2003).

4. Bilinguals in this study were switched-dominance bilinguals who learned Spanish at home and were Spanish dominant until they went to school and were immersed in an English-speaking environment (see Kohnert et al., 1999, for a detailed description). Both the interference and the weaker links accounts of the bilingual effect on picture naming make the same predictions about bilinguals without switched dominance. Because the Spanish-English bilinguals in this study learned English at a later age (see Table 1), relative to the monolinguals, it may seem that differences in the age at which English was learned could explain the bilingual disadvantage. We cannot rule this possibility out; however, it may be unnecessary to assume an age-of-acquisition effect, because bilinguals who learned their dominant language at the same age as monolinguals also demonstrated longer RTs in some language tasks (Ransdell \& Fischler, 1987).

(Manuscript received November 26, 2003; revision accepted for publication October 24, 2004.) 